\title{
Prenatal Diagnosis on Ultrasound, Management and Prognosis of Umbilical Artery Thrombosis: A Retrospective Study of 11 Cases
}

\author{
Suqing Wu \\ Guangdong Provincial People's Hospital, Guangdong Academy of Medical Sciences \\ Hui Chen \\ the People's Hospital of Guangxi Zhuang Autonomous Region, Guangxi Academy of Medical Sciences \\ Yin Wang \\ Guangdong Provincial People's Hospital, Guangdong Academy of Medical Sciences \\ Tingting Hong \\ Guangdong Provincial People's Hospital, Guangdong Academy of Medical Sciences \\ Siwei Luo \\ Guangdong Provincial People's Hospital, Guangdong Academy of Medical Sciences \\ Yanying Liu \\ Guangdong Provincial People's Hospital, Guangdong Academy of Medical Sciences \\ Chunwang Huang ( $\square$ huangchunwang@126.com ) \\ Guangdong Provincial People's Hospital, Guangdong Academy of Medical Sciences
}

\section{Research Article}

Keywords: Umbilical artery thrombosis, Umbilical vessel, Thrombosis, Single umbilical artery, Ultrasound, Fetus

Posted Date: October 26th, 2021

DOI: https://doi.org/10.21203/rs.3.rs-917151/v1

License: (c) (i) This work is licensed under a Creative Commons Attribution 4.0 International License. Read Full License 


\section{Abstract}

\section{Background}

Umbilical artery thrombosis (UAT) is a rare occurrence during pregnancy and is responsible for most of the fetal demises. It is usually difficult to diagnose and easy to be missed or misdiagnosed. The purpose of this study is to investigate the prenatal ultrasonographic and clinical features of UAT.

\section{Methods}

The UAT cases from January 2015 to June 2021 in Guangdong Provincial People's Hospital were collected, and their ultrasonographic and clinical data were analyzed retrospectively.

\section{Results}

11 cases were diagnosed as UAT by intrapartum and postpartum findings. 8 cases (Case 1-8) were diagnosed as UAT by prenatal ultrasound, in which one umbilical vein (UV) and two umbilical arteries (UAs) were detected in the cross and longitudinal sections of the umbilical cord (UC) and thrombi were found in one UA with the obstructed blood flow in the third trimester; however, two UAs with normal blood flow on both sides of fetal bladder were detected during the second trimester. UC punctures were performed before thrombi appeared in 2 cases (Case 7-8). 3 cases (Case 9-11) were misdiagnosed as single umbilical artery (SUA) until delivery. When UAT was diagnosed, the systolic to diastolic ratio (S/D) values of UA were $<$ the $25^{\text {th }}$ percentile and the pulsatility index $(\mathrm{PI})$ values of UA were $<$ the $5^{\text {th }}$ percentile in all cases. Doppler measurements of middle cerebral artery (MCA) were measured in 3 cases. Among them, PI values of MCA of 2 cases were < the $5^{\text {th }}$ percentile, and the cerebroplacental ratios of all 3 cases were $>$ the $25^{\text {th }}$ percentile.

8 pregnancies were terminated by cesarean section. 2 women gave birth spontaneously. 1 woman underwent vaginal forceps delivery. 8 neonates were transferred to neonatal intensive care unit. All the newborns had good prognosis.

\section{Conclusions}

When the ultrasound shows only one UA in the level of fetal bladder for the first time in the third trimester, both sonologists and obstetricians should be highly alert to UAT. Thorough confirm of the previous examination results is necessary to exclude SUA. Intensive fetal monitoring and emergency cesarean section are necessary to avoid adverse perinatal outcomes.

\section{Background}

A normal umbilical cord (UC), as the only connection between the placenta and the fetus, contains two umbilical arteries (UAs) and one umbilical vein (UV) surrounded by Wharton jelly. Umbilical artery thrombosis (UAT), a rare occurrence during pregnancy, which stops the blood flow from the fetus towards the placenta, is associated with adverse perinatal outcomes, such as fetal growth restriction (FGR), abnormal UA flow, neonate thrombotic diseases and even perinatal death $[1,2]$. The etiology of UAT is not yet fully understood. Early prenatal diagnosis, enhancement of fetal monitoring and termination of pregnancy at proper time are the key points to reduce perinatal mortality. Ultrasound is the first choice for the prenatal detection of UC abnormalities. However, UAT is easy to be missed or misdiagnosed in the routine ultrasound examination. So far, the studies focusing on UAT are rare, and most of them are case reports. The prenatal ultrasonic diagnosis and clinical management of UAT remain challenging.

In this article, we summarized the ultrasonic image characteristics and the perinatal data in 11 UAT cases, so as to provide some useful information for clinical management.

\section{Methods}

11 cases diagnosed as UAT by intraoperative findings and postnatal pathology were retrieved from the medical data of 13258 pregnant women who delivered between January 2015 and June 2021 in Guangdong Provincial People's hospital. Our research protocol had been approved by the Research Ethics Committee of Guangdong Provincial People's Hospital, Guangdong Academy of Medical Sciences [No. GDREC2018513H (R1)] and performed in accordance with the guidelines of the Declaration of Helsinki, formulated by the World Medical Association. Written informed consent for participation and publication was obtained from each pregnant woman included in this research.

All of them were examined by serial routine ultrasound in our department during the second and third trimester and the diagnosis was confirmed postnatally. All the scans were performed transabdominally using 3-5MHz transducers (GE Voluson E10/E8). The diagnosis of UAT was confirmed independently by two senior sonologists. Fetuses in the cases diagnosed as UAT were assessed by follow-up ultrasound in 
our department weekly or every other week. Fetal biometry included biparietal diameter, head and abdominal circumference and femur length, and all of them were measured on the basis of guidelines of the International Society of Ultrasound in Obstetrics and Gynecology (ISUOG). Estimated fetal weight was calculated. Fetal gestational age was estimated based on the last menstrual period of pregnant women or ultrasound scan performed during early pregnancy. Examinations of UA were successfully achieved in all cases. Doppler measurements were obtained from both umbilical and middle cerebral arteries (MCA). FGR and fetal distress were evaluated. Torsion of UC, numbers of vessels in UC, thrombi in UA were observed and recorded.

The maternal clinical data were collected, including maternal complications of pregnancy, D-dimer level, mode of delivery, gestational age at delivery. After birth, the length of UC was measured, and the number of complete coils was counted. Placentas with abnormal UC insertions were recorded. Placentas and cords underwent standard histopathological techniques. Stained slides of the placenta and cord microscopic features had been reviewed by two experienced pathologists. The neonatal information was also recorded, including birth weight, newborn sex, Apgar scores and neonatal intensive care unit (NICU) admission.

\section{Results}

Maternal clinical data, pathological findings and neonatal outcomes were available in Table 1. The ultrasonic examination reports were illustrated in Table 2.

Table 1

Maternal clinical data, pathological findings and neonatal outcomes

\begin{tabular}{|c|c|c|c|c|c|c|c|c|c|}
\hline No. & $\begin{array}{l}\text { Maternal } \\
\text { age } \\
\text { (years) }\end{array}$ & $\begin{array}{l}\text { Gravidity } \\
\bigotimes \text { parity }\end{array}$ & $\begin{array}{l}\text { Maternal } \\
\text { Comorbidities }\end{array}$ & $\begin{array}{l}\text { Maternal } \\
\text { D-dimer } \\
\text { (ug/L) }\end{array}$ & $\begin{array}{l}\text { UC } \\
\text { puncture }\end{array}$ & $\begin{array}{l}\text { The last } \\
\text { GA of } 2 \\
\text { UA by } \\
\text { US } \\
\text { (weeks) }\end{array}$ & $\begin{array}{l}\text { GA of } 1 \\
\text { UA by } \\
\text { US } \\
\text { (weeks) }\end{array}$ & $\begin{array}{l}\text { GA of } \\
\text { delivery } \\
\text { (weeks) }\end{array}$ & Fetal movements \\
\hline 1 & 27 & G1P0 & $\begin{array}{l}\text { Severe } \\
\text { Preeclampsia, } \\
\text { Hypothyroidism }\end{array}$ & - & No & $34+2$ & $38+2$ & $38+2$ & Normal \\
\hline 2 & 31 & G1P0 & $\begin{array}{l}\text { GDM, } \\
\text { Antiphospholipid } \\
\text { antibody syndrome }\end{array}$ & 1860 & No & 35 & $37+6$ & $37+6$ & Normal \\
\hline 3 & 29 & G2P1 & None & 1390 & No & $30+3$ & $37+0$ & $37+0$ & Normal \\
\hline 4 & 25 & G1P0 & GDM & 1460 & No & $32+6$ & $39+4$ & $39+4$ & Normal \\
\hline 5 & 25 & G1P0 & $\begin{array}{l}\text { Antiphospholipid } \\
\text { antibody syndrome, } \\
\text { Thalassemia(-SEA/ } \\
\text { aa) }\end{array}$ & 2090 & No & $34+1$ & $37+6$ & $37+6$ & $\begin{array}{l}\text { Admited into hospital } \\
\text { due to the reduction of } \\
\text { fetal movements at } 31 \\
\text { weeks (EFM: Category } \\
\text { I) }\end{array}$ \\
\hline 6 & 35 & G4P1 & None & 5130 & No & $29+$ & $36+4$ & $36+4$ & Normal \\
\hline 7 & 37 & G4P1 & GDM & 2180 & Yes & $30+2$ & $34+4$ & $37+0$ & Normal \\
\hline 8 & 37 & G3P1 & GDM & 1020 & Yes & 24 & $29+1$ & $38+2$ & Normal \\
\hline 9 & 35 & G2P0 & None & - & No & $30+1$ & $37+1$ & $37+4$ & Normal \\
\hline 10 & 35 & G1P0 & None & - & No & $30+6$ & $39+0$ & $39+1$ & Normal \\
\hline 11 & 31 & G3P1 & None & 9830 & No & $32+2$ & $36+5$ & $38+2$ & Normal \\
\hline
\end{tabular}


Table 1

Maternal clinical data, pathological findings and neonatal outcomes (continued)

\begin{tabular}{|c|c|c|c|c|c|c|c|c|c|}
\hline \multirow[t]{2}{*}{ No. } & \multirow[t]{2}{*}{$\begin{array}{l}\text { EFM before } \\
\text { delivery }\end{array}$} & \multirow[t]{2}{*}{$\begin{array}{l}\text { Delivery } \\
\text { mode }\end{array}$} & \multirow[t]{2}{*}{$\begin{array}{l}\text { Amniotic } \\
\text { fluid }\end{array}$} & \multicolumn{2}{|c|}{$\begin{array}{l}\text { Intrapartum and } \\
\text { pathological findings of } \\
\text { cord }\end{array}$} & \multirow[t]{2}{*}{$\begin{array}{l}\text { Birth } \\
\text { weight(g) }\end{array}$} & \multirow[t]{2}{*}{$\begin{array}{l}\text { Apgar } \\
\text { scores }\end{array}$} & \multirow[t]{2}{*}{$\begin{array}{l}\text { Neonate } \\
\text { gender }\end{array}$} & \multirow[t]{2}{*}{$\begin{array}{l}\text { Neonatal follow- } \\
\text { up }\end{array}$} \\
\hline & & & & Intrapartum & Pathological & & & & \\
\hline 1 & Category II & $\begin{array}{l}\text { Emergency } \\
\text { CS }\end{array}$ & Clear & $\begin{array}{l}1 \text { UA: dark } \\
\text { red with } \\
\text { thrombus } \\
\text { seen in it. }\end{array}$ & $\begin{array}{l}\text { Normal } \\
\text { structure of } \\
\text { cord vessels }\end{array}$ & 2590 & $\begin{array}{l}10-10- \\
10\end{array}$ & $\mathrm{~F}$ & $\begin{array}{l}\text { Admited to NICU } \\
\text { for observation }\end{array}$ \\
\hline 2 & Category II & $\begin{array}{l}\text { Emergency } \\
\text { CS }\end{array}$ & $\begin{array}{l}\text { Meconium- } \\
\text { stained }\left(I^{\circ}\right)\end{array}$ & $\begin{array}{l}1 \text { UA was } \\
\text { dark red } \\
\text { with } \\
\text { thrombus } \\
\text { seen in it. }\end{array}$ & $\begin{array}{l}\text { Normal } \\
\text { structure of } \\
\text { cord vessels }\end{array}$ & 3030 & $\begin{array}{l}10-10- \\
10\end{array}$ & $M$ & Normal \\
\hline 3 & $\begin{array}{l}\text { Category III } \\
\text { (prolonged } \\
\text { deceleration) }\end{array}$ & $\begin{array}{l}\text { Emergency } \\
\text { CS }\end{array}$ & Clear & $\begin{array}{l}\text { Hyper- } \\
\text { coiling } \\
\text { cord; Part } \\
\text { of } 1 \text { UA } \\
\text { was dark } \\
\text { red with } \\
\text { thrombus } \\
\text { seen in it. }\end{array}$ & $\begin{array}{l}\text { Normal } \\
\text { structure of } \\
\text { cord vessels }\end{array}$ & 2725 & $9-9-9$ & $M$ & $\begin{array}{l}\text { VSD; cTGA; } \\
\text { Pulmonary } \\
\text { hypertension }\end{array}$ \\
\hline 4 & Category II & $\begin{array}{l}\text { Emergency } \\
\text { CS }\end{array}$ & Clear & $\begin{array}{l}1 \text { UA was } \\
\text { dark red } \\
\text { with } \\
\text { thrombus } \\
\text { seen in it. }\end{array}$ & $\begin{array}{l}\text { Normal } \\
\text { structure of } \\
\text { cord vessels }\end{array}$ & 3085 & $\begin{array}{l}6-10- \\
10\end{array}$ & $M$ & $\begin{array}{l}\text { Cyanosis; Mild } \\
\text { asphyxia }\end{array}$ \\
\hline 5 & Category I & $\begin{array}{l}\text { Spontaneous } \\
\text { vaginal } \\
\text { delivery }\end{array}$ & Clear & $\begin{array}{l}1 \text { UA was } \\
\text { dark red } \\
\text { with } \\
\text { thrombus } \\
\text { seen in in. }\end{array}$ & $\begin{array}{l}\text { Normal } \\
\text { structure of } \\
\text { cord vessels }\end{array}$ & 2795 & $\begin{array}{l}10-10- \\
10\end{array}$ & $\mathrm{M}$ & $\begin{array}{l}\text { Admited to NICU } \\
\text { for observation }\end{array}$ \\
\hline 6 & Category I & $\begin{array}{l}\text { Emergency } \\
\text { CS }\end{array}$ & Clear & $\begin{array}{l}\text { Hyper- } \\
\text { coiling } \\
\text { cord; Part } \\
\text { of } 1 \text { UA } \\
\text { was dark } \\
\text { red with } \\
\text { thrombus } \\
\text { seen in it. }\end{array}$ & $\begin{array}{l}\text { Normal } \\
\text { structure of } \\
\text { cord vessels }\end{array}$ & 2630 & $\begin{array}{l}8-10- \\
10\end{array}$ & $\mathrm{~F}$ & Normal \\
\hline 7 & Category I & $\begin{array}{l}\text { Emergency } \\
\text { CS }\end{array}$ & Clear & $\begin{array}{l}\text { Hyper- } \\
\text { coiling } \\
\text { cord; Part } \\
\text { of } 1 \text { UA } \\
\text { was dark } \\
\text { red with } \\
\text { thrombus } \\
\text { seen in it. }\end{array}$ & $\begin{array}{l}\text { Normal } \\
\text { structure of } \\
\text { cord vessels }\end{array}$ & 2180 & $\begin{array}{l}10-10- \\
10\end{array}$ & $M$ & $\begin{array}{l}\text { NEC; Rescued } \\
\text { for apnea; } \\
\text { Anticoagulant } \\
\text { therapy due to } \\
\text { the rising of } \\
\text { blood clotting } \\
\text { function }\end{array}$ \\
\hline 8 & Category I & Elective CS & Clear & $\begin{array}{l}\text { Part of } 1 \\
\text { UA was } \\
\text { earthy- } \\
\text { yellow with } \\
\text { thrombus } \\
\text { seen in it. }\end{array}$ & $\begin{array}{l}\text { Normal } \\
\text { structure of } \\
\text { cord } \\
\text { vessels; } \\
\text { Thrombus } \\
\text { in } 1 \mathrm{UA} \text {; The } \\
\text { infarction of } \\
\text { arterial } \\
\text { vascular } \\
\text { wall }\end{array}$ & 2710 & $\begin{array}{l}10-10- \\
10\end{array}$ & $\mathrm{~F}$ & $\begin{array}{l}\text { Admited to NICU } \\
\text { for observation }\end{array}$ \\
\hline 9 & Category I & $\begin{array}{l}\text { Spontaneous } \\
\text { vaginal } \\
\text { delivery }\end{array}$ & $\begin{array}{l}\text { Meconium- } \\
\text { stained } \\
\left(I I^{\circ}\right)\end{array}$ & - & $\begin{array}{l}\text { Normal } \\
\text { structure of } \\
\text { cord vessels }\end{array}$ & 2535 & $\begin{array}{l}10-10- \\
10\end{array}$ & $M$ & Normal \\
\hline
\end{tabular}

UC: umbilical cord; GA: gestational age; UA: umbilical artery; US: ultrasound; GDM: gestational diabetes mellitus; EFM: electronic fetal heart monitoring; CS: cesarean section; F: female; NICU: neonatal intensive care unit; M: male; VSD: ventricular septal defect; cTGA: complete transposition of the great artery; NEC: necrotizing enterocolitis 


\begin{tabular}{|c|c|c|c|c|c|c|c|c|c|}
\hline \multirow[t]{2}{*}{ No. } & \multirow[t]{2}{*}{$\begin{array}{l}\text { EFM before } \\
\text { delivery }\end{array}$} & \multirow[t]{2}{*}{$\begin{array}{l}\text { Delivery } \\
\text { mode }\end{array}$} & \multirow[t]{2}{*}{$\begin{array}{l}\text { Amniotic } \\
\text { fluid }\end{array}$} & \multicolumn{2}{|c|}{$\begin{array}{l}\text { Intrapartum and } \\
\text { pathological findings of } \\
\text { cord }\end{array}$} & \multirow[t]{2}{*}{$\begin{array}{l}\text { Birth } \\
\text { weight(g) }\end{array}$} & \multirow[t]{2}{*}{$\begin{array}{l}\text { Apgar } \\
\text { scores }\end{array}$} & \multirow[t]{2}{*}{$\begin{array}{l}\text { Neonate } \\
\text { gender }\end{array}$} & \multirow[t]{2}{*}{$\begin{array}{l}\text { Neonatal follow- } \\
\text { up }\end{array}$} \\
\hline & & & & Intrapartum & Pathological & & & & \\
\hline 10 & Category I & $\begin{array}{l}\text { Forceps } \\
\text { delivery }\end{array}$ & $\begin{array}{l}\text { Meconium- } \\
\text { stained } \\
\left(111^{\circ}\right)\end{array}$ & - & $\begin{array}{l}\text { Normal } \\
\text { structure of } \\
\text { cord vessels }\end{array}$ & 3300 & $\begin{array}{l}10-10- \\
10\end{array}$ & M & $\begin{array}{l}\text { Shortness of } \\
\text { breath; } \\
\text { Meconium } \\
\text { aspiration } \\
\text { syndrom }\end{array}$ \\
\hline 11 & Category I & Elective CS & Clear & $\begin{array}{l}\text { Hyper- } \\
\text { coiling cord }\end{array}$ & $\begin{array}{l}\text { Normal } \\
\text { structure of } \\
\text { cord vessels }\end{array}$ & 3820 & $\begin{array}{l}10-10- \\
10\end{array}$ & $M$ & $\begin{array}{l}\text { Cyanosis; } \\
\text { Wet lung disease }\end{array}$ \\
\hline
\end{tabular}


Table 2

The ultrasonic examination reports of 11 UAT cases

\begin{tabular}{|c|c|c|c|c|c|c|c|c|c|c|c|}
\hline No. & $\begin{array}{l}\text { Vanishing } \\
\text { side of } \\
\text { UA }\end{array}$ & $\begin{array}{l}\text { Number } \\
\text { of } \\
\text { vessels } \\
\text { in UC in } \\
\text { previous } \\
\text { US scan }\end{array}$ & $\begin{array}{l}\text { Number } \\
\text { of } \\
\text { vessels } \\
\text { in UC by } \\
\text { US in the } \\
\text { 3rd } \\
\text { trimester }\end{array}$ & $\begin{array}{l}\text { Thrombus } \\
\text { in the UA } \\
\text { by US }\end{array}$ & $\begin{array}{l}\text { Cord } \\
\text { around } \\
\text { neck }\end{array}$ & $\begin{array}{l}\text { S/D } \\
\text { (UA) }\end{array}$ & $\begin{array}{l}\mathrm{PI} \\
\text { (UA) }\end{array}$ & $\begin{array}{l}\text { PI } \\
\text { (MCA) }\end{array}$ & CPR & $\begin{array}{l}\text { Prenatal } \\
\text { diagnosis } \\
\text { by US }\end{array}$ & $\begin{array}{l}\text { Other US } \\
\text { findings }\end{array}$ \\
\hline 1 & $\mathrm{R}$ & 3 & 3 & Seen & Yes & $\begin{array}{l}1.48 \\
(<5 \text { th } \\
)^{2}\end{array}$ & $\begin{array}{l}0.41 \\
(<5 \text { th } \\
)^{(4)}\end{array}$ & $\begin{array}{l}0.92 \\
(<5 \text { th } \\
)^{(10}\end{array}$ & $\begin{array}{l}2.24 \\
(>75 \text { th })\end{array}$ & UAT & - \\
\hline 2 & $\mathrm{R}$ & 3 & 3 & Seen & No & $\begin{array}{l}1.66 \\
(<10 \text { th }\end{array}$ & $\begin{array}{l}0.51 \\
(<5 \text { th } \\
)^{-1}\end{array}$ & - & - & UAT & VSD \\
\hline 3 & $\mathrm{~L}$ & 3 & 3 & Seen & Yes & $\begin{array}{l}1.69 \\
(<10 \text { th } \\
)\end{array}$ & $\begin{array}{l}0.54 \\
(<5 \text { th } \\
)^{2}\end{array}$ & - & - & UAT & cTGA \\
\hline 4 & $\mathrm{R}$ & 3 & 3 & Seen & Yes & $\begin{array}{l}1.75 \\
(<25 \text { th } \\
)\end{array}$ & $\begin{array}{l}0.57 \\
(<5 \text { th } \\
)^{2}\end{array}$ & $\begin{array}{l}0.86 \\
(<5 \text { th } \\
)^{(10}\end{array}$ & $\begin{array}{l}1.51(25 \text { th } \\
-50 \text { th })\end{array}$ & UAT & - \\
\hline 5 & $\mathrm{~L}$ & 3 & 3 & Seen & Yes & $\begin{array}{l}1.85 \\
(<25 \text { th } \\
)^{1}\end{array}$ & $\begin{array}{l}0.62 \\
(<5 \text { th } \\
)^{2}\end{array}$ & - & - & UAT & - \\
\hline 6 & $\mathrm{R}$ & 3 & 3 & Seen & Yes & $\begin{array}{l}1.55 \\
(<5 \text { th }\end{array}$ & $\begin{array}{l}0.44 \\
(<5 \text { th } \\
)^{2}\end{array}$ & - & - & UAT & - \\
\hline 7 & $L$ & 3 & 3 & Seen & Yes & $\begin{array}{l}1.59 \\
(<5 \text { th } \\
)^{2}\end{array}$ & $\begin{array}{l}0.45 \\
(<5 \text { th } \\
)^{-1}\end{array}$ & - & - & $\begin{array}{l}\text { 34+ w: } \\
\text { SUA } \\
37+\text { w: } \\
\text { UAT }\end{array}$ & $\begin{array}{l}\text { FGR; Hyper- } \\
\text { coling UC }\end{array}$ \\
\hline 8 & $L$ & 3 & 3 & Seen & Yes & $\begin{array}{l}2.23 \\
(<25 \text { th } \\
)\end{array}$ & $\begin{array}{l}0.74 \\
(<5 \text { th } \\
)^{2}\end{array}$ & $\begin{array}{l}2.11 \\
(>75 \text { th } \\
)^{2}\end{array}$ & $\begin{array}{l}2.85 \\
(>95 \text { th })\end{array}$ & UAT & $\begin{array}{l}\text { Velamentous } \\
\text { placenta; } \\
\text { Aberrant } \\
\text { right } \\
\text { subclavian } \\
\text { artery }\end{array}$ \\
\hline 9 & $\mathrm{R}$ & 3 & 2 & $\begin{array}{l}\text { Maybe } \\
\text { ignored }\end{array}$ & Yes & $\begin{array}{l}1.55 \\
(<5 \text { th }\end{array}$ & $\begin{array}{l}0.44 \\
(<5 \text { th } \\
)^{2}\end{array}$ & - & - & SUA & - \\
\hline 10 & $\mathrm{~L}$ & 3 & 2 & $\begin{array}{l}\text { Maybe } \\
\text { ignored }\end{array}$ & Yes & $\begin{array}{l}1.74 \\
(<25 \text { th } \\
)\end{array}$ & $\begin{array}{l}0.56 \\
(<5 \text { th } \\
)^{-5}\end{array}$ & - & - & SUA & - \\
\hline 11 & $\mathrm{~L}$ & 3 & 2 & $\begin{array}{l}\text { Maybe } \\
\text { ignored }\end{array}$ & No & $\begin{array}{l}1.56 \\
(<5 \text { th }\end{array}$ & $\begin{array}{l}0.47 \\
(<5 \text { th } \\
)^{2}\end{array}$ & - & - & SUA & - \\
\hline
\end{tabular}

Among these 13258 pregnant women (13607 fetuses), a total of 11 cases were diagnosed as UAT by intrapartum and pathological findings (newborn sex: male 8, female 3), bringing the prevalence of UAT to 8/10,000. 4 women were primiparas and 7 women were multiparas. 9 pregnancies were conceived naturally while the other 2 were conceived by assisted reproductive technology. Mean maternal age was $31.5 \pm 4.6$ years old (range 25 to 37 years old), and the number of pregnancies range from 1 to 4 (average $2.1 \pm 1.2$ ) times. The gestational age at delivery was $37.9 \pm 0.9$ weeks (range $36^{+4}$ to $39^{+4}$ weeks). 6 women suffered from pregnant complications (4 with gestational diabetes mellitus, Case 2, 4, 7, 8; 1 with severe preeclampsia and hypothyroidism, Case 1; 2 with antiphospholipid antibody syndrome, Case 2, 5; 1 with thalassemia, Case 5), and the other 5 had no complications. UC puncture was performed in 2 cases (Case 7-8), and no fetal abnormalities were found in chromosome kyryotype analysis and chromosome mircoarray examinations. 
In all cases, only one UA was incidentally found at the level of fetal bladder by routine ultrasound examination in the third trimester (range $29^{+1}$ to $39^{+4}$ weeks) (Figure $1 \mathrm{~B}, 4 \mathrm{~A}, 6 \mathrm{~B}, 6 \mathrm{E}$ ), however with a history of two UAs previously detected in the second trimester (Figure $1 \mathrm{~A}, 2 \mathrm{~A}, 6 \mathrm{~A}$ 6D). 8 cases (72.72\%) (Case 1-8) were successfully and correctly diagnosed as UAT before delivery. Among them, three vessels, one UV and two UAs, could be seen in the cross and longitudinal section of UC by prenatal ultrasound. More importantly, thrombus in one UA and blood flow obstructed by the thrombi were also observed (Figure 1C, 2B-2E, 3A-3B, 4B-4E, 5A-5B, 5D-5E). Case 7 was misdiagnosed as single umbilical artery (SUA) at 34+ weeks, since only one UA at the level of fetal bladder was found (Figure 6B), but the thrombus in the other UA was missed (Figure 6C). The diagnosis was corrected to UAT at 37+ weeks by follow-up ultrasound, when thrombus, hyper-coiling, and FGR were detected at the same time. No hyper-coiling was found by ultrasound in the other cases.

3 cases (27.27\%) (Case 9-11) were misdiagnosed as SUA in the third trimester, of which the history of two UAs in previous ultrasound scans were ignored by examiners (Figure 6D) and thrombi were out of detection (Figure 6F).

U-fetal neck pressure traces could be seen before or at the same time with the detection of UAT in 9 cases (Case 1, 3-10) (81.8\%).

Doppler measurements of the unobstructed UA such as systolic to diastolic ratio (S/D) and pulsatility index (PI) values were completely achieved. When UAT was diagnosed, the S/D values of UA (UA-S/D) were less than the 25th percentile in 4 cases, less than the 10 th percentile in 2 cases and less than the 5th percentile in 5 cases (Case 1, 6, 7, 9, 11) [3]. The PI values of UA (UA-PI) were less than the 5th percentile in all cases (Figure 7A) [4]. Doppler measurements of MCA were measured in only 3 cases (Case 1, 4, 8) [4]. The PI values of MCA were less than the 5th percentile in 2 cases (Case 1, 4) (Figure 7B), nevertheless, the cerebroplacental ratios (CPR) were higher than the 25th percentile in all of those 3 cases (Case 1, 4, 8) [4].

7 women (Case 1-7) were admitted into hospital due to the finding of UAT by ultrasound ( 6 women at term, Case 1-5, 7; 1 woman at $36+$ weeks of gestational age, Case 6), and 6 of them were given emergency cesarean section to terminate the pregnancy (Case 1-4, 6-7). The woman in Case 5 was ever admitted to hospital at 31+ weeks of gestational age due to the reduction of fetal movements but the electronic fetal heart rate monitoring (EFM) manifested normal during hospitalization. Later at 37+ weeks, she delivered the baby via vagina rapidly after admission, although an emergency cesarean section was suggested by the obstetrician due to the ultrasound report of UAT.

EFM was performed in all cases. 4 of them (Case 1-4) had unsatisfactory EFM (category II or III according to a 3-tiered system for categorization, ACOG guideline, 2009 [5]) before the termination of pregnancy. Case 8 was diagnosed as UAT at 29+ weeks with a normal estimated fetal weight, blood flow by ultrasound. Considering the poor prognosis of premature infant, the obstetrician advised the woman to follow-up with ultrasound scan and EFM more frequently and pay more attention to fetal movement until delivery. Finally, the fetus was delivered at term (38+ weeks) by elective cesarean section with scarred uterus as the indication.

In those 3 cases (Case 9-11) misdiagnosed as SUA by prenatal ultrasound, the pregnant women had no pregnant complications, and their follow-up ultrasound scans and EFM were normal. Finally, they gave birth at full term (Case 9: spontaneous vaginal delivery; Case 10: vaginal forceps delivery; Case 11: elective cesarean section with scarred uterus as the indication).

Meconium-stained amniotic fluid was found in 3 cases (Case 2, 9, 10). Gross examination of placenta and UC showed that all the cords were in normal length, and hyper-coiling cords were found in 4 cases (Case 3, 6, 7, 11). The pathological findings showed the structure of cord vessels (two UAs and one UV) was normal in all cases, and only 1 pathological report (Case 8) described the existence of thrombus in one of the UAs and the infarction of arterial vascular wall (Figure 5C, 5F). In accordance with the intrapartum findings, one UA was dark red in 7 cords (Case 1-7) (Figure 1D, 3C) and earthy-yellow in 1 cord (Case 8) (Figure 4F), with thrombus found in them. Unfortunately, the intrapartum description about the UA appearance could not be obtained in Case 9-11. Velamentous placenta was reported in Case 8.

All newborns were born alive with normal birth weights (2922 $\pm 399 \mathrm{~g})$, except Case 7 with a low-birth-weight infant (2180g). In Case 4, Apgar score at 1 and 5 minutes was 6 and 10, respectively, and those in the other cases were $>7$ at 1 and 5 minutes. 8 neonates (Case 1, 3-5, 7-8, 1011) were transferred to NICU. The neonate in Case 3 was admitted for receiving surgical treatment because of ventricular septal defect (VSD), complete transposition of the great artery (cTGA) and pulmonary hypertension. The neonate in Case 4 suffered from intrauterine distress during delivery accompanied by poor intrapartum EFM, and gradually developed cyanosis for mild asphyxia half an hour later. During hospitalization, the neonate in Case 7 was diagnosed as neonatal necrotizing enterocolitis (NEC) and rescued for apnea. He was also treated with anticoagulant therapy since the blood clotting function continued to rise. The neonate in Case 10 was hospitalized with shortness of breath due to meconium aspiration syndrome, and the neonate in Case 11 with cyanosis for wet lung disease. 3 Neonates (Case 1, 5, 8) were regarded as high-risk and transferred to NICU for observation because of the maternal complications during pregnancy. All of them were treated well and their prognosis was good.

\section{Discussion}


UAT is a vascular disease with thrombi in one or both UAs, which can directly or indirectly affect the maternal-fetal circulation and leads to adverse perinatal outcomes. Since it has been rarely reported, its exact incidence remains uncertain. Heifetz [6] reported the incidence of UC thrombosis in deliveries, perinatal autopsies and high-risk pregnancies were approximately $0.08 \%, 0.1 \%$ and $0.4 \%$, respectively. In our retrospective study, one single UAT was diagnosed in only 11 of 13258 pregnancies (13607 fetuses) postnatally, bringing the prevalence of $0.08 \%$. Compared to UV thrombosis, UAT occurred less frequently [6]. However, it was more inclined to lead to adverse perinatal outcomes and was responsible for $80 \%$ of the stillbirths [6]. Sato et al. [7] reviewed 11 fetuses with UAT retrospectively, $38 \%$ of them were related to severe FGR and 25\% led to intrauterine demise. Shilling et al. [8] reported 7 fetuses with one single UAT. Among them, 3 suffered from FGR, 2 were stillborn [8]. All neonates had been through an abnormal process and hypoperfusion was shown in all placentas [8]. Even though the blood flow of the unobstructed UA, amniotic fluid volume and fetal growth parameters in the third trimester are in normal range, UAT is still a life threaten event and the fetus could die suddenly without being noticed [9]. Thus, it is necessary to identify UAT more effectively by prenatal ultrasound, so proper clinical management can follow up as soon as possible.

At present, the etiology and pathogenesis of UAT have not been completely clarified. Hypercoagulability, blood flow stasis and endothelial injury are supposed to be the main reasons for thrombosis formation. As for UAT, it may be the same. It is well known that pregnant women are in a physiologic hypercoagulable state that can result in thromboembolism more easily. Hypercoagulability may be related to maternal genetic or acquired factors, for example, the unstable level of blood glucose of diabetes disrupting the coagulation function by affecting the expression of endothelial factors [10]. Not only maternal gestational diabetes mellitus, but also smoking and other complications during pregnancy such as hypertensive disease and thrombophilia can induce the formation of clots in UA [1, 2, 11]. Abnormal UC anatomy, mechanical injury of the UC, and pathological state of fetus or pregnant woman may be the high-risk factors for thrombosis of UC [6]. Cord abnormalities such as anatomical dysplasia, abnormal length (too long or too short), reduction of diameter, unusual Wharton jelly morphology, anomalous placental insertion, twisting, tieing, true knot, excessive helix or compression may induce flow stasis and lead to thrombi of UA $[2,7,11-13]$. According to studies in recent years, UAT might be closely related to accidental injury of the artery via unpremeditated UV puncture when inserting the needle into the cord [14]. Coincidentally, in our series, 2 out of 11 cases had undergone UV puncture. Consequently, we speculate that UV puncture is also a thrombophilia-related inducer. And there were 9 cases with U-fetal neck pressure traces before or when UAT was diagnosed by ultrasound, which implied cord-around-neck might cause blood flow stasis relating to thrombus formation. Avagliano et al. [11] considered the intrauterine infection could damage the vascular endothelium and caused inflammation and thrombus of umbilical vessels. Additionally, it was believed that protein $S$ deficiency of the fetus which influenced the state of anticoagulant material in the endothelium of blood vessels might play an important part in the thrombosis of UA [1]. In our study, 1 newborn (Case 7) suffered from NEC, which might be related to the formation of intestinal microthrombi. 2 fetuses (Case 2,3 ) were complicated with cardiac malformation (VSD and cTGA, respectively). However, whether intestinal microthrombi and fetal heart diseases are associated with UAT or not needs to be analyzed in further studies with larger sample.

Before UAT occurs, UC usually develops normally. Two-dimensional ultrasound imaging shows that the transverse section of UC includes three circular structures, of which the larger one is UV while the two smaller ones are UAs (Figure 2A), and the longitudinal section of the cord is arranged in a spiral form, which shows all of the three vessels are unobstructed. Color doppler imaging shows two UAs on both sides of the bladder and the vessels in the cord are in "one red two blue" or "one blue two red" structure in which different color means the opposite directions of blood flow. As shown in the ultrasound images of the cases in our study, when thrombosis in one UA occurs, the structure of three vessels can still be seen in the transverse and longitudinal section of UC. One UA is normal and the other one becomes thinner with thrombus filling inside in a hypoechoic or hyperechoic way by two-dimensional ultrasound (Figure 2B, 2D, 3A, 4B-4C, 4E, 5A, 5D, 6F). Color Doppler imaging shows only one UA is displayed on either side of the bladder, while the blood flow of the other UA is obstructed by thrombus in the bladder level (Figure 1B, 4A, 6B, 6E) and in the free segment of UC (Figure 1C, 2C, 2E, 3B, 4D, 5B, 5E, 6C). Some cases were accompanied by excessive helix of UC (Figure 3A-B, 4B, 4D, 6C). Thrombus observed in the lumen of one UA can be used as a direct sign to diagnose UAT. It is worth noting that ultrasonographic appearance of thrombus may be different depending on the occurrence time and the range of thrombosis.

It is easy to misdiagnose one single UAT as SUA when only one UA is found on either side of the bladder by prenatal ultrasound in the third trimester. Persutte et al. [15] inferred that the main reasons for the occurrence of SUA might be congenital agenesis or dysplasia and gradual disappearance of one UA in the later development, even both probabilities might coexist. The incidence of SUA reported in literature was around $0.31 \%$ [16], which was significantly higher than that of UAT. Due to the fact that SUA is associated with the congenital dysplasia of UC, it is detectable as early as 12 weeks of gestation age by modern ultrasonography equipment [17], while UAT usually occurs during the third trimester. Thus, it becomes possible for making the prenatal diagnosis of UAT via comparing the patient's initial ultrasound scans, in which two arteries could be clearly seen in the cord, with later ultrasound images in the third trimester, which shows the pathological manifestation of UAT. However, when it comes to the cases without any routine ultrasound examination data before, the differentiation can only rely on the sonographic manifestation in late pregnancy. Compared to one single UAT, two-dimensional ultrasound imaging of SUA shows only two vessels, one artery and one vein, in the cord through the whole pregnancy. Color Doppler flow imaging shows only one UA on 
either side of the fetal bladder and the umbilical vessels are in "one red and one Blue", which represents different directions of blood flow. Besides thrombi observed in the artery, which was recognized as the direct sign of UAT, a distinctive ultrasonic sign of UAT found by Klaritsch et al. [18] was that one clogged UA was in parallel with the other unobstructed one and surrounded by UV, like 'an orange grabbed by a hand' in the transverse section of the umbilical cord. Moreover, Tanaka et al. [19] regarded 'Orange grabbed sign' might stand for hyper-coiling of UC, meanwhile, it was suggested as a repeatable and innovative way of UAT diagnosis. In our series, 'Orange grabbed sign' could be observed in Case 7 (Figure 4E) and Case 9 (Figure 6F). Since this sign is totally different from the ultrasound manifestation of SUA in the transverse section, it can be used for the differentiation between UAT and SUA.

In our study, thrombi could not be found in 3 cases (27.27\%) (Case 9-11) by prenatal ultrasound, and they were misdiagnosed as SUA. 1 case (Case 7) had been misdiagnosed as SUA and the diagnosis was corrected to UAT in later examination. The possible explanation for this might be as follows: (1) The examiners lacked fully understanding of the implications of the presence of one single UAT. Thus, the ultrasonic history in the second trimester was often ignored and they failed to spend enough time in examining the vasculature of cord to find out the thrombi. (2) There were some technical difficulties, such as the blockage by fetus in the third trimester and examiners' lack of training of complete observation of UC and thrombi in the artery. (3) Excessively spiral cord might cause narrower vascular lumen of UA, which made small thrombi hard to be detected. (4) The clots had formed for a long time and were gradually absorbed, so that it was too tiny to be detected. Therefore, comprehending the different formation mechanisms and ultrasonic manifestations of one single UAT and SUA is conducive to differentiate them from each other and improve the diagnostic accuracy. For those suspected cases, even if no direct signs of thrombi are observed, the diagnosis of UAT cannot be denied.

In our study, UA-S/D values were less than the 25th percentile and UA-PI values less than the 5 th percentile. It was reported by Sepulveda et al. [20] that there was a compensatory increase of UA diameter in SUA since the entire blood flow was transported through only one UA. The patho-physiological changes might the same in UAT. We speculate that when one of the UAs is embolized, the other one will dilate in compensation to maintain the blood flow from the fetus to the placenta. Thus, the velocity of diastolic flow in the dilated UA increases in the whole cardiac cycle and the values of UA-S/D and UA-PI decrease relatively. Besides, our result showed an increase of ventricular diastolic velocity and a decrease of PI value of MCA (MCA-PI) in the spectrum Doppler. Due to the fact that the PI values of the unobstructed UAs are decreased, CPR (MCA-PI/UA-PI) tends to be normal. These changes might be related to fetal brain-sparing effect when one UA was obstructed. When intrauterine hypoxia occurs, fetal brain-sparing effect will be activated, with the cerebral arteries dilating and vascular resistance in ventricular diastole reducing, so that the cerebral perfusion can be maintained [21]. Hershkovitz et al. [22] found the resistance index of MCA in fetuses with SUA were similar to that in fetuses with a normal UC including two arteries. Currently, the vascular resistance indices of UA and MCA are being used to judge if there is intrauterine hypoxia. Whether they can also be used to differentiate UAT from SUA remains to be further confirmed.

SUA is associated with the high incidence of fetal anomaly. It was reported by Murphy-Kaulbeck et al. [23] that the fetuses and neonates with SUA had greater risks of congenital malformations and chromosomal abnormalities, 6.77 and 15.35 times respectively. Trisomy 18 and 21 were the most common chromosomal abnormalities [17]. Therefore, the prenatal identification of SUA by ultrasound may be helpful in the antenatal detection of congenital anomalies and aneuploidy. Xu et al. [24] implied that isolated SUA dramatically raised the risk for fetus of small for gestational age. Thus, when SUA fetuses are found by prenatal ultrasound, it needs not only to find out structural abnormalities of the fetuses, but also to assess their growth and development. Prenatal diagnosis for chromosomal anomalies and genetic counseling should be suggested. For the cases with the coexistence of only one UA displayed in the third trimester and fetal structural abnormalities, SUA should be suspected, which may be helpful in the differentiation between UAT and SUA.

According to the existing data, the standard of ultrasound scan and EFM frequency after the prenatal UAT diagnosis and the timing of pregnancy termination are absent. In Zhu's opinion [25], when the signs of fetal intrauterine distress (reduction of fetal movement, abnormal EFM) appeared, the occurrence of UC thrombosis should be vigilant of, and ultrasound scan should be conducted seriously as well. For term pregnancy, emergency cesarean section should be performed without hesitation in order to avoid serious fetomaternal conditions [25]. For preterm cases, the duration of expectant management remained uncertain, and the timing to terminate pregnancy depended on the supportive capacity of NICU for premature neonates [25]. Dussaux et al. [26] reported a case of UV thrombosis diagnosed at 32 weeks of gestation with a slightly increased resistance index of UA found by Doppler ultrasound, in which close follow-up (daily EFM and weekly ultrasound scans) was suggested instead of emergency cesarean section after the diagnosis. Although the fetus died in utero 3 days later, the authors still insisted on expectant management and intensive fetal monitoring for the UC thrombosis cases before 37 weeks of gestational age on the basis of risk-benefit balance [26]. Luckily, in our study, the incidence of perinatal complications was not as high as reported in the literature, with only one fetus (9.09\%) suffering from FGR. All fetuses were born alive, and their prognosis was good. The main reason might be most of the thrombosis were found by ultrasound prenatally, so that fetuses could benefit from the immediate clinical managements by obstetricians. Even if 3 cases (Case 9-11) were misdiagnosed as SUA, whose pregnancies were lucky to last without close surveillance until spontaneous delivery or elective cesarean section at term, and 1 case (Case 8) was given expectant management until full-

Page 9/17 
term, we still recommended that emergency cesarean section should be performed once thrombus was found by ultrasound scan during term pregnancy. Fetal demise may happen all of a sudden without any warning. For preterm cases, even though EFM and ultrasound indices are normal during expectant management, the pregnancy should also be terminated by cesarean section once the gestational age exceeding 32 weeks, after the promotion of fetal lung maturation by corticosteroid therapy.

\section{Conclusion}

In summary, UAT is a rare occurrence and cannot be easily diagnosed during antenatal examination. For cases with only one UA was displayed for the first time in the third trimester by prenatal ultrasound, especially for cases underwent UV puncture, UAT should be highly suspected. Double-checking the previous ultrasound examinations for two vascular structures of UA and the existence of thrombi in one UA was the most useful way to differentiate one single UAT from SUA. For suspected or diagnosed UAT cases, the frequency of follow-up EFM and ultrasound examination should be increased, and the termination of pregnancy should be performed at the proper time.

\section{Abbreviations}

UC: umbilical cord

UA: umbilical artery

UV: umbilical vein

UAT: umbilical artery thrombosis

FGR: fetal growth restriction

MCA: middle cerebral artery

NICU: neonatal intensive care unit

SUA: single umbilical artery

S/D: systolic to diastolic ratio

PI: pulsatility index

UA-S/D: S/D value of UA

UA-PI: PI value of UA

CPR: cerebroplacental ratio

EFM: electronic fetal heart monitoring

VSD: ventricular septal defect

cTGA: complete transposition of the great artery

NEC: necrotizing enterocolitis

MCA-PI: PI value of MCA

\section{Declarations}

\section{Ethics approval}

Our research protocol had been approved by the Research Ethics Committee of Guangdong Provincial People's Hospital, Guangdong Academy of Medical Sciences [No. GDREC2018513H (R1)] and performed in accordance with the guidelines of the Declaration of Helsinki, formulated by the World Medical Association.

\section{Consent to participate}




\section{Consent for publication}

Written informed consent for the publication of the clinical data and ultrasound images was obtained from each participant woman.

\section{Availability of data and materials}

The data used and analysed during the current study are available from the corresponding author on reasonable request.

\section{Competing interests}

The authors declare that they have no competing interests.

\section{Funding}

This work was supported by the Guangzhou Municipal Science and Technology Planning Project (CN) (202002030235), Medical Scientific Research Foundation of Guangdong Province (A2019080).

\section{Authors' contributions}

Suqing Wu and Hui Chen contributed to the conception of the study. Yin Wang and Yanying Liu performed the ultrasonography of 11 UAT cases. Suqing Wu, Tingting Hong and Siwei Luo collected the clinical data. Suqing Wu and Hui Chen analyzed the ultrasonic and clinical data. Suqing Wu and Hui Chen wrote the main manuscript text. Chunwang Huang assisted in manuscript editing and provided the funding. All authors reviewed and approved the final manuscript. Each author can respond to any questions in regard to this study in their area of expertise.

\section{Acknowledgements}

We would like to thank Yantao Zhao of Laurentin University, Sudbury, Ontario, Canada for English language editing.

\section{References}

1. Ali Alhousseini, Sunil Jaiman, Edgar Hernandez-Andrade, Salam Zeineddin, Faisal Qureshi, Suzanne M Jacques. Umbilical Artery Thrombosis with Associated Acute and Severe Fetal Growth Restriction and Transient Severe Protein S Deficiency: Report of a Case with Prenatal Ultrasound Diagnosis Allowing for Timely Intervention and Good Outcome. Case Rep Obstet Gynecol. 2018 Jul 9;2018:6324362.

2. Gustavo Henrique de Oliveira, Cristiane de Moraes Dias, Denise Cristina Mós Vaz-Oliani, Antonio Hélio Oliani. Intrauterine thrombosis of umbilical artery - case report. Sao Paulo Med J. 2016 Jul-Aug;134(4):355-8.

3. Ganesh Acharya, Tom Wilsgaard, Gro K Rosvold Berntsen, Jan Martin Maltau, Torvid Kiserud. Reference ranges for serial measurements of umbilical artery Doppler indices in the second half of pregnancy. Am J Obstet Gynecol. 2005 Mar;192(3):937-44.

4. A Ciobanu, A Wright, A Syngelaki, D Wright, R Akolekar, K H Nicolaides. Fetal Medicine Foundation reference ranges for umbilical artery and middle cerebral artery pulsatility index and cerebroplacental ratio. Ultrasound Obstet Gynecol. 2019 Apr;53(4):465-72.

5. ACOG Practice Bulletin No. 106: Intrapartum fetal heart rate monitoring: nomenclature, interpretation, and general management principles. Obstet Gynecol. 2009 Jul;114(1):192-202.

6. S A Heifetz. Thrombosis of the umbilical cord: analysis of 52 cases and literature review. Pediatr Pathol. 1988;8(1):37-54.

7. Y Sato, K Benirschke. Umbilical arterial thrombosis with vascular wall necrosis: clinicopathologic findings of 11 cases. Placenta. 2006 Jun-Jul;27(6-7):715-8.

8. Christine Shilling, Colin Walsh, Paul Downey, Eoghan Mooney. Umbilical artery thrombosis is a rare but clinically important finding: a series of 7 cases with clinical outcomes. Pediatr Dev Pathol. 2014 Mar-Apr;17(2):89-93.

9. Fouad Lutfallah, Nina Oufkir, Georges A Markou, Delphine Frimigacci, Christophe Poncelet. A Case of Umbilical Artery Thrombosis in the Third Trimester of Pregnancy. Am J Case Rep. 2018 Jan 19;19:72-75. 
10. M A Fritz, C R Christopher. Umbilical vein thrombosis and maternal diabetes mellitus. J Reprod Med. 1981 Jun;26(6):320-4.

11. Laura Avagliano, Anna Maria Marconi, Massimo Candiani, Antonino Barbera, Gaetano Bulfamante. Thrombosis of the umbilical vessels revisited. An observational study of 317 consecutive autopsies at a single institution. Hum Pathol. 2010 Jul;41(7):971-9.

12. Joanna S Y Chan, Rebecca N Baergen. Gross umbilical cord complications are associated with placental lesions of circulatory stasis and fetal hypoxia. Pediatr Dev Pathol. 2012 Nov-Dec;15(6):487-94.

13. Hong Qi Peng, Michelle Levitin-Smith, Burton Rochelson, Ellen Kahn. Umbilical cord stricture and overcoiling are common causes of fetal demise. Pediatr Dev Pathol. 2006 Jan-Feb;9(1):14-9.

14. Roopali V Donepudi, Kenneth J Moise Jr. Intrauterine Transfusion Complicated by Umbilical Artery Thrombosis. Case Rep Obstet Gynecol. 2019 Feb 20;2019:5952326.

15. W H Persutte, J Hobbins. Single umbilical artery: a clinical enigma in modern prenatal diagnosis. Ultrasound Obstet Gynecol. 1995 Sep;6(3):216-29.

16. A S Gornall, J J Kurinczuk, J C Konje. Antenatal detection of a single umbilical artery: does it matter?. Prenat Diagn. 2003 Feb;23(2):11723.

17. G Rembouskos, S Cicero, D Longo, C Sacchini, K H Nicolaides. Single umbilical artery at 11-14 weeks' gestation: relation to chromosomal defects. Ultrasound Obstet Gynecol. 2003 Dec;22(6):567-70.

18. P Klaritsch, M Haeusler, E Karpf, D Schlembach, U Lang. Spontaneous intrauterine umbilical artery thrombosis leading to severe fetal growth restriction. Placenta. 2008 Apr;29(4):374-7.

19. Kei Tanaka, Shinji Tanigaki, Miho Matsushima, Noriko Miyazaki, Reiko Hashimoto, Tomoko Izawa, Keiji Sakai, Takuya Yazawa, Mitsutoshi Iwashita. Prenatal diagnosis of umbilical artery thrombosis. Fetal Diagn Ther. 2014;35(2):148-50.

20. W Sepulveda, M J Peek, J Hassan, J Hollingsworth. Umbilical vein to artery ratio in fetuses with single umbilical artery. Ultrasound Obstet Gynecol. 1996 Jul;8(1):23-6.

21. S Degani. Fetal cerebrovascular circulation: a review of prenatal ultrasound assessment. Gynecol Obstet Invest. 2008;66(3):184-96.

22. Reli Hershkovitz, Eyal Sheiner, Moshe Mazor. Middle cerebral artery blood flow velocimetry among healthy fetuses with a single umbilical artery. J Ultrasound Med. 2006 Nov;25(11):1405-8; quiz 1409-10.

23. Lynn Murphy-Kaulbec, Linda Dodds, K S Joseph, Michiel Van den Hof. Single umbilical artery risk factors and pregnancy outcomes. Obstet Gynecol. 2010 Oct;116(4):843-50.

24. Yajuan Xu, Lidan Ren, Shanshan Zhai, Xiaohua Luo, Teng Hong, Rui Liu, Limin Ran, Yingying Zhang. Association Between Isolated Single Umbilical Artery and Perinatal Outcomes: A Meta-Analysis. Med Sci Monit. 2016 Apr 30;22:1451-9.

25. Ying Zhu, Rajluxmee Beejadhursing, Yanyan Liu. 10 cases of umbilical cord thrombosis in the third trimester. Arch Gynecol Obstet. 2021 Jul;304(1):59-64.

26. Chloé Dussaux, Olivier Picone, Guillemette Chambon, Mikael Tassin, Jelena Martinovic, Alexandra Benachi, Anne-Gaël Cordier. Umbilical vein thrombosis: to deliver or not to deliver at the time of diagnosis?. Clin Case Rep. 2014 Dec;2(6):271-3.

\section{Figures}




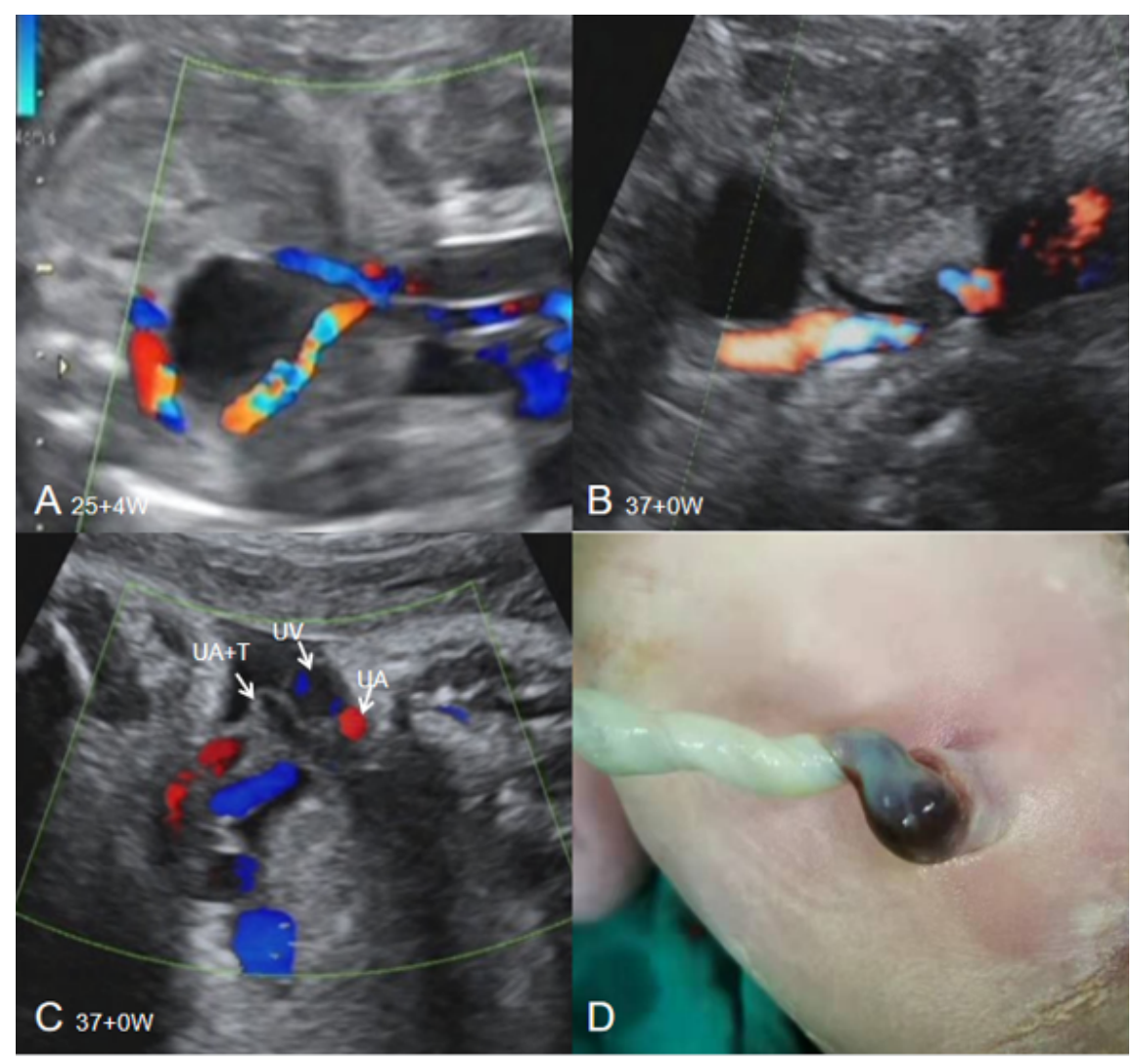

\section{Figure 1}

Case 3 A. (25+4w) 2 UAs seen on both sides of fetal bladder; B. (37w) Only 1 UA seen at the level of fetal bladder; C. (37w) Color Doppler imaging showing blood flow in 1 UA blocked by the thrombus $(T)$ near the umbilicus; $D$. Intrapartum findings showing the thrombus existing in the cord near the umbilicus

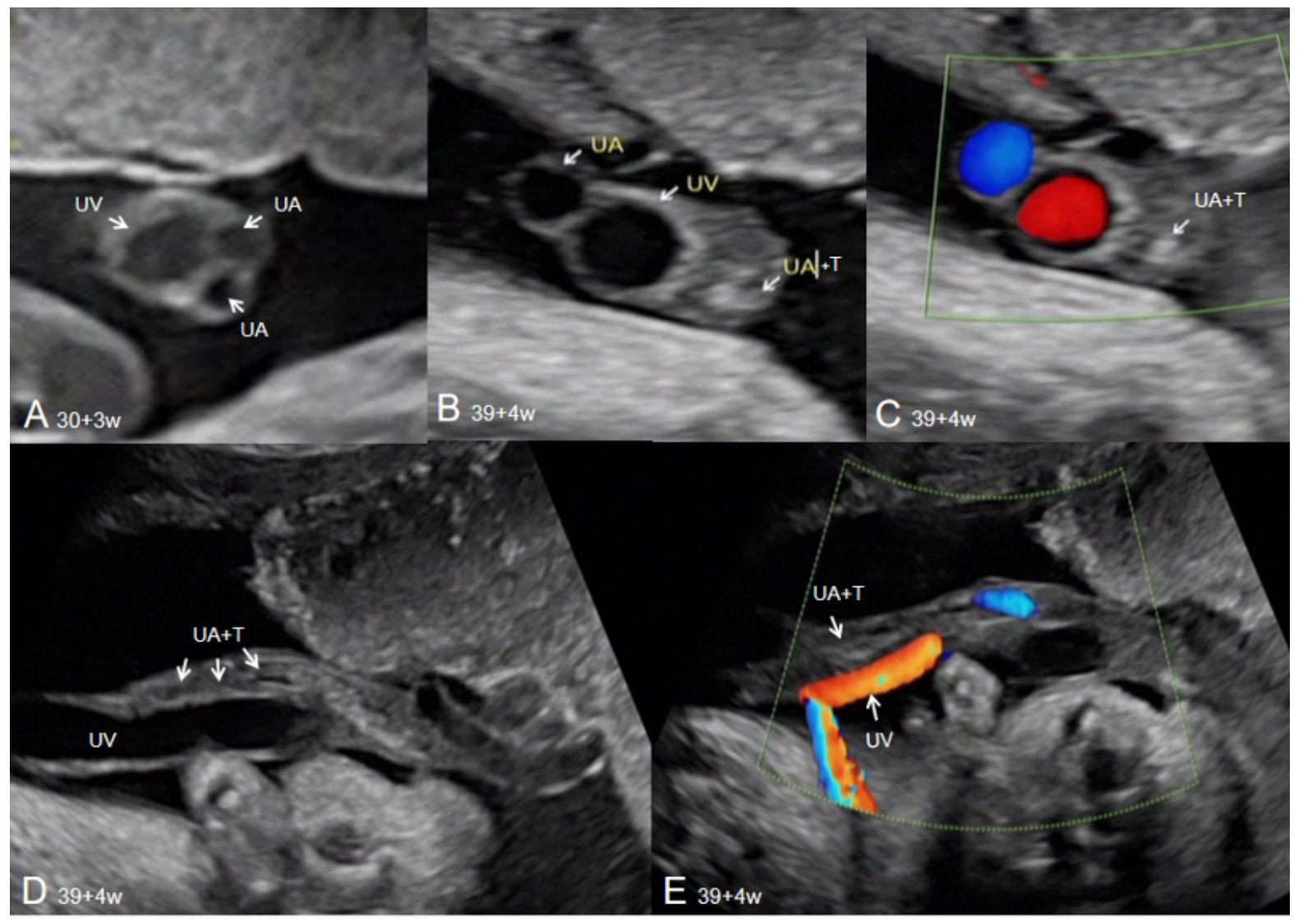

Figure 2 
Case 4 A. (30+3w) Transverse-sectional imaging of UC showing 2 UAs and 1 UV; B, D. (39+4w) Transverse and longitude sectional imaging of UC showing the thrombus (T) seen in $1 \mathrm{UA} ; \mathrm{C}, \mathrm{E}$. $(39+4 \mathrm{w})$ Color Doppler imaging of Figure 2B and 2D showing blood flow blocked by the thrombus $(T)$

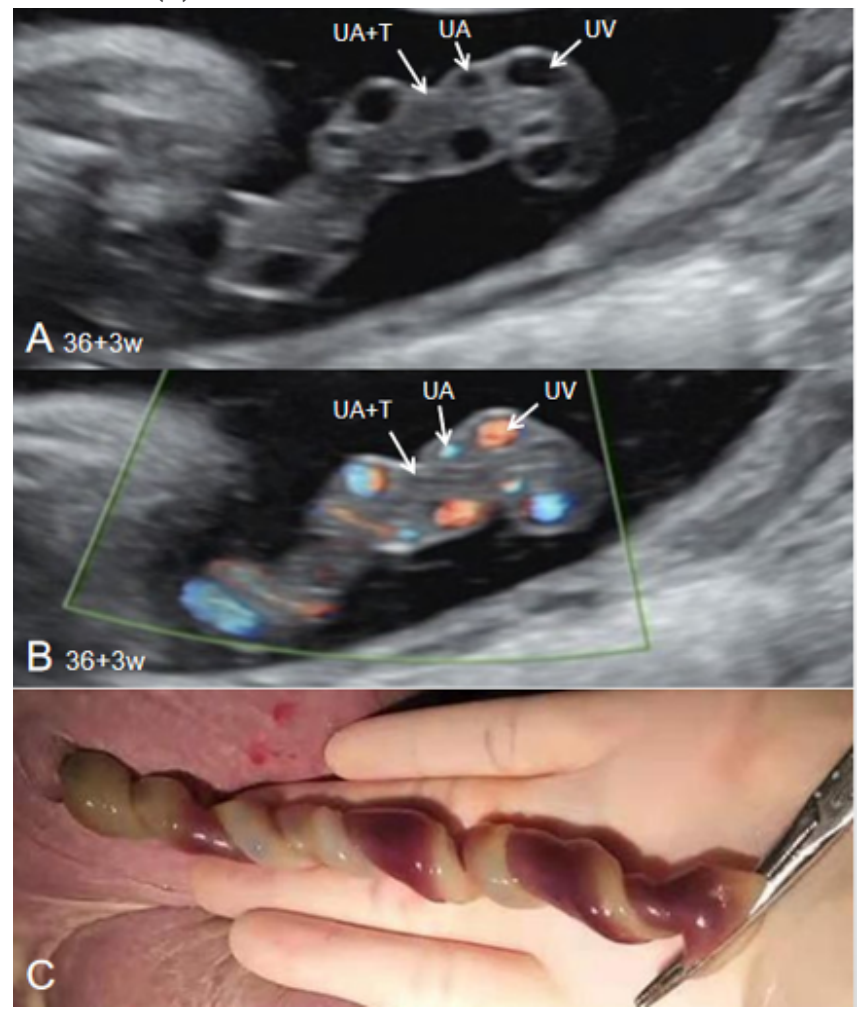

\section{Figure 3}

Case 6 A. (36+3w) 1 UA thrombus (T) with hyper-coiling UC; B. (36+3w) Color Doppler imaging showing blood flow in 1 UA blocked by the thrombus $(T)$ in Figure $3 A$; $C$. Intrapartum findings showing the thrombus in red existing in the hyper-coiling cord

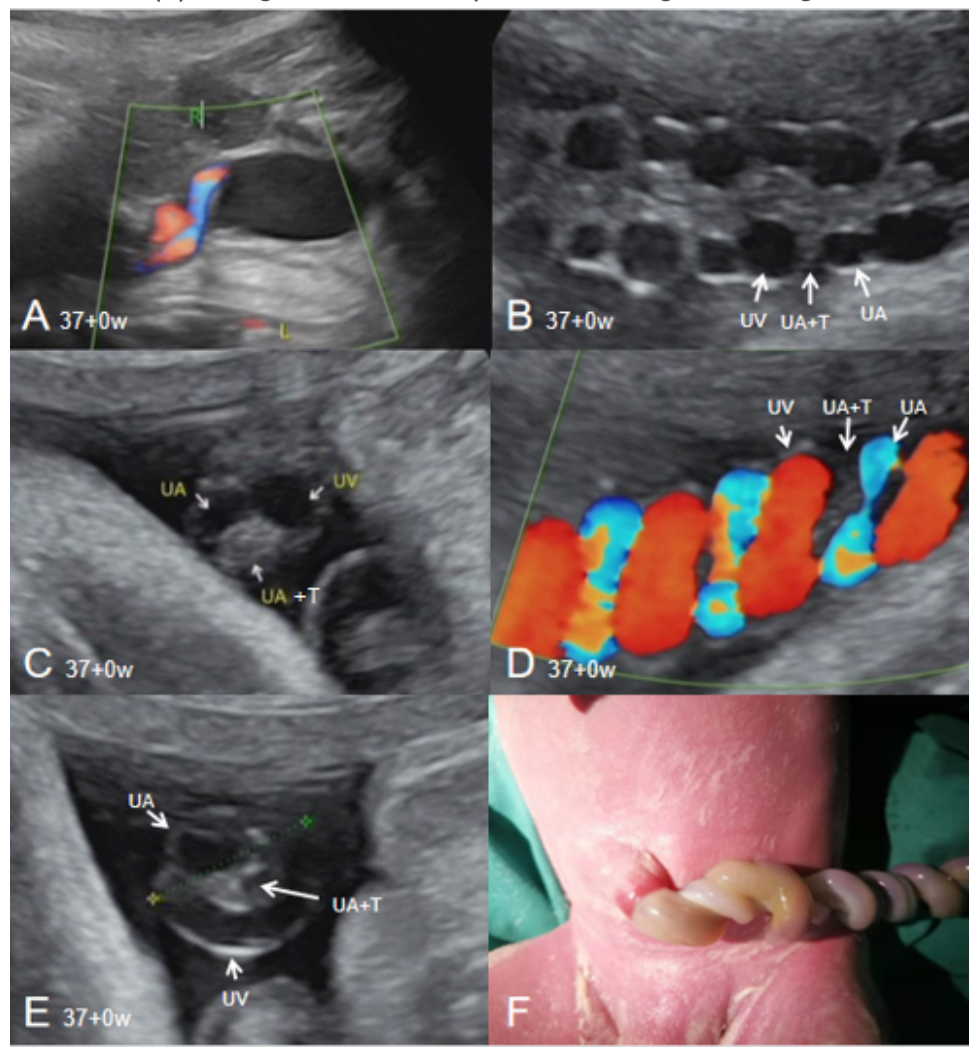

Figure 4 
Case 7 A. (37w) Only 1 UA seen at the level of fetal bladder; B. (37w) 1 UA thrombus (T) with hyper-coiling UC; C. (37w) Transverse-sectional imaging of UC showing thrombus seen in $1 \mathrm{UA}$; D. (37w) Color Doppler imaging of Figure 4B showing blood flow in 1 UA blocked by thrombus (T); E. (37w) 'Orange grabbed sign': 1 clogged UA was in parallel with the other unobstructed one and surrounded by UV; F. Intrapartum findings showing the thrombus existing in the hyper-coiling cord

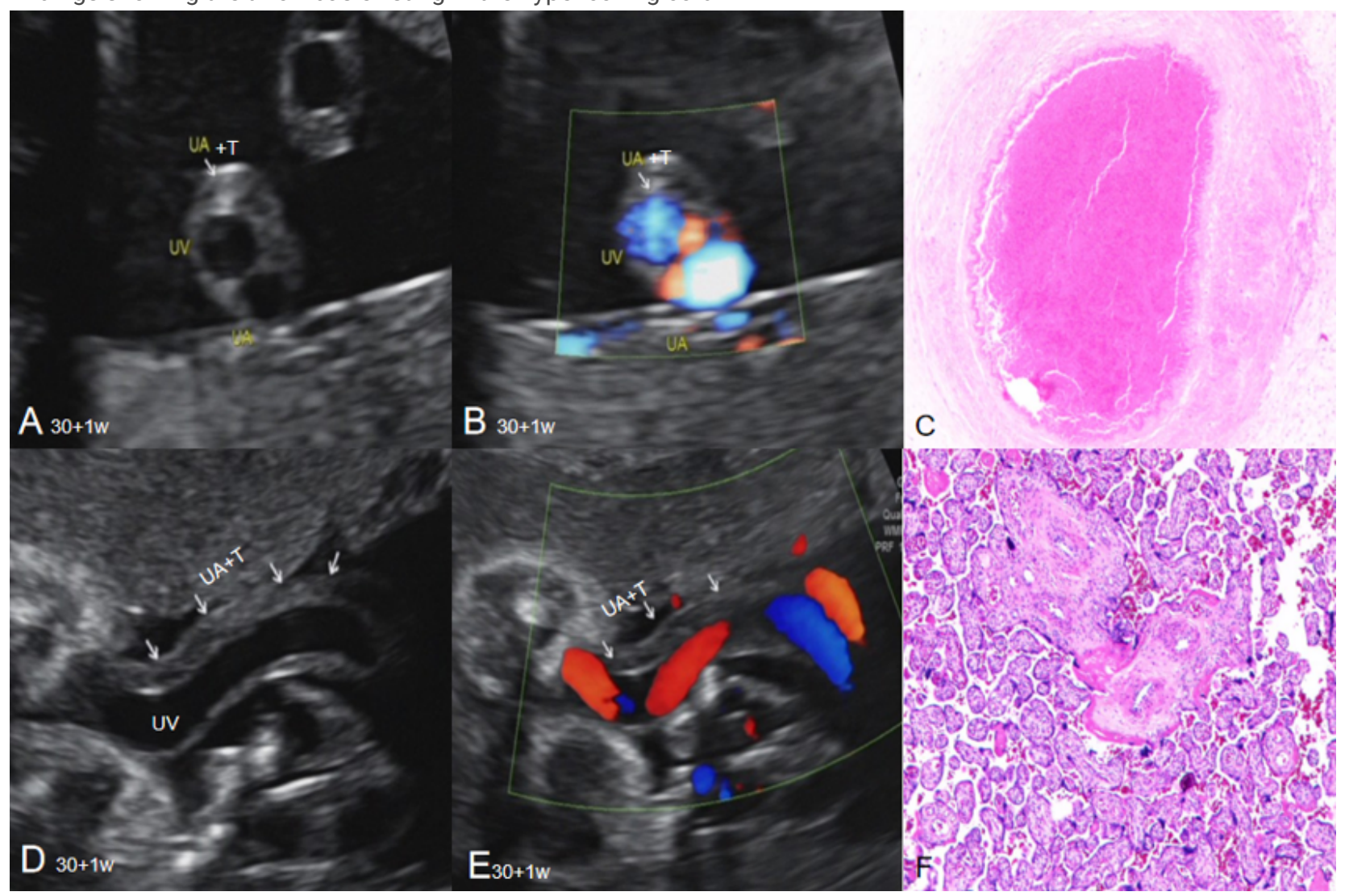

\section{Figure 5}

Case 8 A, D. (30+1w) Transverse and longitude sectional imaging of UC showing thrombus (T) seen in 1 UA; B, E. (30+1w) Color Doppler imaging of Figure 5A and 5D showing blood flow blocked by the thrombus (T); C, F: Pathological findings showing the thrombus in UA 




\section{Figure 6}

Case 7 A. $(22+4 w) 2$ UAs seen on both sides of fetal bladder; B. (34+4w) Only 1 UA seen at the level of fetal bladder; C. (34+4w) Color Doppler imaging showing blood flow blocked by the thrombus (T) in 1 UA Case 9 D. $(24+4 w) 2$ UAs seen on both sides of fetal bladder; E. (37+1 w) Only 1 UA seen at the level of fetal bladder; F. (37+1w) 1 UA thrombus ( $T$ ) and 'Orange grabbed sign' seen in the transverse section of UC 




\section{Figure 7}

Case 4. (39+4w) A-B. Spectral Doppler ultrasound of UA and MCA showing increased diastolic blood flow and low PI values 